\title{
EMPREENDEDORISMO SOCIAL E CRESCIMENTO ECONÔMICO SUSTENTÁVEL: UMA CONTRIBUIÇÃO TEÓRICA
}

Eúde Do Amor Cornélio ${ }^{1}$

Regina Ávila Santos ${ }^{2}$

Monica Cristina Rovaris Machado ${ }^{1}$

Darlane Amorim Vieira ${ }^{1}$

\footnotetext{
${ }^{1}$ Universidade Federal de Sergipe

2 Universidade Federal do Rio Grande
} 


\section{EMPREENDEDORISMO SOCIAL E CRESCIMENTO ECONÔMICO SUSTENTÁVEL: UMA CONTRIBUIÇÃO TEORICA}

Resumo: Os padrões econômicos pré-estabelecidos não mais atendem às questões vivenciadas pela sociedade que busca por novos modelos de gestão, demandando novo modelo de desenvolvimento. Após observação da lacuna de pesquisa sobre de que forma o incentivo ao empreendedorismo social pode levar países em desenvolvimento a atingir o Objetivo de Desenvolvimento Sustentável oito (Emprego Digno e Crescimento Econômico) conforme sugerido pela Organização das Nações Unidas-ONU, objetiva-se responder como o Empreendedorismo Social (ES) em uma estrutura integrada, pode ser capaz de promover o desenvolvimento econômico sustentável, gerando emprego digno para os stakeholders. Para tanto, utiliza-se o método bibliográfico com temáticas que envolvem sustentabilidade e redes colaborativas que atendam aos objetivos da pesquisa. Foi percebido que elas auxiliam no desenvolvimento do ES, reafirmam a identidade dos empreendedores e contribuem para a correção de externalidades com uma melhora na qualidade de vida dos atores, além de geração de renda e emprego digno.

Palavras-chave: Empreendedorismo Social. Sustentabilidade. Redes colaborativas. Crescimento Econômico.

\section{$1 \quad$ Introdução}

O modelo de desenvolvimento nas economias contemporâneas, baseado na grande produção e consumo de bens e serviços, impõe uma acentuada pressão sobre os recursos naturais, provocando, em alguns casos, danos irreversíveis à natureza, seja em nível local, regional ou global, comprometendo o equilíbrio dos ecossistemas e interferindo na reorganização dos sistemas econômicos produtivos.

Os debates acerca do tema voltam-se para o entendimento de como conciliar a satisfação das necessidades humanas (ilimitadas), contrapondo com os recursos naturais disponíveis (limitados), vislumbrando a qualidade do processo de desenvolvimento. Neste sentido, pode-se encontrar no Empreendedorismo Social (ES) inserido numa estrutura integrada, um meio de levar o desenvolvimento econômico de maneira sustentável às nações.

No Brasil, as primeiras experiências de ES surgem na década de 1980, tendo seus empreendimentos surgido apenas em 1990, podendo-se destacar a Associação Saúde Criança e o Comitê para Democratização da Informática, ambos no Rio de Janeiro, o Banco Palmas, em Fortaleza (Limeira, 2015) e o Graacc (combate ao câncer infantil), entre outras iniciativas nas diversas regiões do país.

Conforme Zahra, Rawhouser, Neubaum, Hayton (2008), há quatro fatores cruciais que alimentam a globalização do empreendedorismo social, destacando-se: a disparidade de riqueza global; o movimento de responsabilidade social das empresas; as falhas de mercado, institucionais e estaduais; e os avanços tecnológicos e responsabilidade compartilhada.

Entende-se aqui por falhas de mercado as situações em que o mercado por si só não consegue estabelecer o preço e a quantidade para gerar eficiência, ou seja, as forças de 
mercado não conseguem assegurar resultados ótimos. Apresenta-se-nos, então, o problema de como a política do governo pode intervir, a fim de que haja uma alocação de recursos mais eficiente. (Musgrave, 1976; Meirelles, 2010).

Para Oliveira (2004), tanto o conceito como a prática do empreendedorismo social derivam de entendimentos e intenções frente à vontade de mudar o cenário causado pelos impactos de uma globalização de efeitos paradoxais, que ao mesmo tempo em que gera riqueza e ciência e tecnologia, também produz um gigantesco exército de famintos e excluídos, produzidos principalmente pela desigualdade social e econômica, marcada e acentuada pela concentração de renda e problemas sociais históricos, principalmente para os chamados países do terceiro e quarto mundo. (Oliveira, 2004)

São duas as temáticas as quais a desigualdade envolve: a que diz respeito a desigualdade existente entre as pessoas, relacionada a qualidade de vida e geralmente resumida pela renda, tendo como aspecto principal não o nível de renda, mas a desigualdade existente em sua distribuição e a da desigualdade regional, causada pelos altos níveis de diferenças existentes entre as regiões brasileiras, independente dos critérios utilizados para sua mensuração. (Vilar, 2017)

Este artigo tem como objetivo compreender como o empreendedorismo social em uma estrutura integrada, pode ser capaz de promover o desenvolvimento econômico sustentável, auxiliando na correção das falhas de mercado, gerando emprego digno e produtivo para os envolvidos. A lacuna de pesquisa está em averiguar como o incentivo ao empreendedorismo social pode levar países como o Brasil a atingir o Objetivo de Desenvolvimento Sustentável (ODS) oito (8 - Emprego Digno e Crescimento Econômico) para um Desenvolvimento Sustentável, conforme sugerido pela Organização das Nações Unidas - ONU.

Para tanto, utiliza-se o método exploratório por meio de pesquisa bibliográfica com temáticas da literatura nacional e estrangeira que envolvem empreendedorismo, sustentabilidade e redes de interação mediante autores considerados relevantes para o tema, buscando-se conexão entre o empreendedorismo social e o desenvolvimento econômico sustentável, com a utilização de redes colaborativas como ferramenta de ampliação das relações sociais ao redor do globo.

Sendo assim, este estudo divide-se em três seções, que compreendem a esta breve introdução, seguida da revisão de literatura que discute os diferentes contextos e aspectos que englobam as relações de empreendedorismo como forma viável ao desenvolvimento sustentável e geração de emprego e renda e finaliza com as discussões e conclusões.

Através da discussão proposta, espera-se contribuir na compreensão da forma em que o incentivo ao empreendedorismo social aliado às redes colaborativas pode atuar no desenvolvimento econômico-sustentável local, aumentando a geração de emprego, renda e diminuindo as desigualdades regionais.

\section{Revisão da Literatura}

Desde os anos 1980, houve um enorme crescimento nos estudos sobre empreendedorismo. Tais estudos tendem a estar preocupados com o indivíduo, e os aspectos puramente econômicos de iniciar uma nova empresa e subsequente desenvolvimento de negócios. Os estudos relacionados ao empreendedorismo social, foram inicialmente introduzidos por Banks (1972). Neste trabalho, ele usou o termo para descrever as 
necessidades de usar habilidades gerenciais para abordar problemas sociais e desafios de negócios (Spear, 2006; El Ebrashi, 2013).

Nesse ínterim entre empreendedorismo de negócios (EN) e empreendedorismo social (ES), vale a ressalva de que diferentemente do primeiro que possui foco em retornos econômicos, o ES prioriza o retorno social. (Austin, Stevenson, Wei-Skillern, 2012) Logo, o ES emerge como uma abordagem inovadora para lidar com necessidades sociais complexas, através de iniciativas que tenham a criação de valor social como seu principal objetivo estratégico, que orientam sua missão de modo criativo e inovador (Bose, 2012).

Portanto, o ES contribui na solução e atendimento das necessidades da sociedade, entre elas o desequilíbrio econômico e a vulnerabilidade social a que estão submetidos, principalmente os países em desenvolvimento (Desai, 2014), apresentando papel crucial no desenvolvimento econômico e na criação de valor social, e dessa forma, atendendo as necessidades dos agentes envolvidos neste processo de forma progressista e transdisciplinar (Jiao, 2011).

Pode-se destacar os empreendedores sociais financeiros, como Muhammad Yunus, fornecem um serviço social de suma importância para a geração de valor social e fomento para o desenvolvimento sustentável, ao passo que, oferecem meios para o surgimento de novos empreendimentos sociais, gerando emprego e renda para indivíduos marginais à sociedade ou discriminados. Em 1976, Yunus cria o primeiro negócio social que busca oferecer microcrédito para a população da base da pirâmide econômica em Bangladesh, $\mathrm{O}$ Grameen Bank de Bangladesh, que ao mesmo tempo em que é capaz de gerar lucro através de suas atividades, proporciona impacto positivo na sociedade. (Limeira, 2015)

Para Yunus, o conceito de ES combina a maximização do impacto socioambiental positivo e da sustentabilidade econômico-financeira sem a distribuição de lucros. Este modelo representa uma oposição ao conceito tradicional de empreendedorismo, que implica a distribuição dos lucros. Para ele, a empresa social procura alcançar objetivos sociais e portanto, o princípio econômico básico de maximização de lucros deve ser substituído pelo benefício social (Yunus, 2008; 2010).

É certo que tanto nacional quanto internacionalmente o conceito ainda está em construção. Apesar disso, há um consenso na compreensão da origem do ES e da sua participação no enfrentamento dos problemas sociais. Essa relação próxima e até histórica tem diferenças significativas, que nos auxiliam a compreender e melhor definir o que seja o ES na atualidade (Oliveira, 2004).

Dees (1998) enfatiza que empreendedores sociais tem uma missão social que, associada à gestão empresarial, a inovação e a determinação, conseguem proporcionar benefícios sociais duradouros à população e para isso, necessitam de disciplina, inovação e determinação. Para Machado, Lenzi e Penalva (2017), o empreendedorismo social envolve a criatividade na promoção de mudanças sociais, e estas ocorrem com longo alcance em seus campos de atividade, pois os indivíduos fomentadores dessa prática são inovadores e possuem capacidade empreendedora.

Para Mair e Marti (2006), o ES é um processo que consiste no uso inovador e combinação de recursos para exploração e aproveitamento de oportunidades, que visa catalisar a mudança social através da restauração das necessidades humanas básicas de uma 
maneira sustentável. Assim, o ES combina elementos do empreendedorismo tradicional com o propósito de inovar na ordem social (Seelos \& Mair, 2005).

Apesar de controverso por ser um tema novo, diversos autores convergem na abordagem das escolas de pensamento sobre o ES, tais como Machado, Lenzi e Penalva (2017), Comini, Barki e Aguiar (2012) lizuka, Walchhutter, Romani-Dias, Barbosa (2014). Em comum, apresentam as três principais abordagens sobre o conceito do ES: norteamericana, que emerge como chave nas necessidades sociais pelo caráter omisso do papel do Estado e apresenta uma abordagem liberal e individualista, com regulação mínima do estado e da proteção social, aproximando-se como um substituto do Estado de Bem Estar Social, não se preocupando com o fato de existir pobreza, mas pela questão moral e de caridade. Europeia, que surge do movimento associativista na Europa no século XIX junto com a Economia Social, influenciada pelo socialismo utópico, liberalismo e social cristianismo, objetivando garantir a dignidade das condições de vida das populações desprotegidas, visto que a capacidade do Estado em satisfazer as necessidades sociais era limitada. Utilizam o termo empresa social e através das práticas de ES, representam o que chamam de Terceiro Setor baseada no trabalho associado, associações de desenvolvimento local, ONG, dentre outras. Finalmente, a escola de países em desenvolvimento, com foco nas iniciativas de mercado destinadas a reduzir a pobreza e alterar as condições sociais dos indivíduos marginalizados ou excluídos. Nesta abordagem, há uma subdivisão: empreendimentos com receita e despesas equilibradas, sem perdas monetárias, sem dividendos a distribuir aos membros e sem fins lucrativos, onde os ganhos são reinvestidos para ampliação e melhoria do empreendimento; empreendimentos com obtenção de lucros, propriedade das pessoas consideradas pobres e objetivo previamente definido, sendo mais apropriado utilizar a forma de negócios sociais com fins lucrativos.

Como visto anteriormente, há muitos e diversificados conceitos de ES, que se caracterizam por meio da estrutura que se deseja analisar em determinado empreendimento social. Filion (1999, p.14) reforça a ampla variedade de pontos de vista usados para estudar o fenômeno e por esta razão, neste artigo, adotamos o conceito apresentado pela rede de universidades iberoamericanas Social Enterprise Knowledge Network (SEKN), que conceitualizam o ES como organizações ou empresas que geram mudanças sociais por meio de atividades de mercado. Uma vez que, tal abordagem inclui ONGs e organizações sem fins lucrativos ou organizações do setor privado diretamente envolvidas em atividades comerciais genuínas do setor público, produção de produtos e serviços de alto valor econômico. (Comini, Barki \& Aguiar, 2012) Esta abordagem se constitui mais geral em termos de abrangência de agentes que compõem e se utilizam do ES como ferramenta de auxílio ao desenvolvimento econômico via correção de externalidades provocadas tanto por agentes públicos como privados. Para direcionar a discussão proposta aqui, adota-se também a dimensão da terceira abordagem do conceito de ES, países em desenvolvimento.

É certo que o êxito das atividades do ES que emergem para atender a necessidade da criação de valor social está intimamente ligado à relação entre capital humano e seu grau de conveniência e viabilidade. Quando empreendedores sociais percebem que possuem um alto grau de capital humano, concluem que possuem maior capacidade de iniciar novos empreendimentos sociais. (Jiao, 2011) 
Essa relação afeta diretamente o capital social da empresa, que, segundo Recuero (2005) constitui-se em um conjunto de recursos de um determinado grupo, obtido através da comunhão dos recursos individuais, que pode ser usufruído por todos os membros do grupo, ainda que individualmente, e que está baseado na reciprocidade. Ele está embutido nas relações sociais e é determinado pelo conteúdo delas.

Pode-se afirmar que a organização é composta pela interação social que constitui as relações de determinado grupo, que podem ser acumulados, aprofundando um determinado laço e aumentando o sentimento de grupo. (Recuero, 2005) Assim, as redes sociais são definidas por Junqueira (2000, p. 40) como "um conjunto de pessoas e organizações que se relacionam para responder às demandas e às necessidades da população de maneira integrada, respeitando o saber e a autonomia de cada membro." Frente a questões sociais apresentadas na atual conjuntura, empreendimentos sociais encontram nas redes uma alternativa de ampliar o alcance e a profundidade do seu trabalho. (Silva, Moura e Junqueira, 2015)

Dentre os fatores organizacionais que compõem um empreendimento social, o capital social aliado às redes de relacionamentos sociais se torna elemento útil no alcance dos objetivos a que se propõe a organização, visto que elas influenciam positivamente o seu desenvolvimento. Por estar em constante transformação (Marques, 2007) as redes de relacionamentos estabelecidos evoluem e se aprofundam à medida em que os empreendedores dos casos provam a sua confiabilidade. (Ducci \& Teixeira, 2011)

Assim, Recuero (2009) destaca que enquanto os atores representam os nós da rede em questão, as conexões de uma rede social podem ser percebidas de diversas maneiras. Em termos gerais, elas são constituídas dos laços sociais, que, por sua vez, são formados através da interação social entre os atores.

$\mathrm{Na}$ medida em que as redes sociais e as parcerias são constituídas, há a possibilidade de aumentar a amplitude da transformação social, pois por meio da interação social existe a possibilidade de compartilhar conhecimentos, experiências e recursos no processo de gerar uma teia social que viabiliza laços de solidariedade e troca. A autonomia dos atores nas suas decisões, tomadas de forma coletiva e horizontal, possibilitam a democratização no enfrentamento das demandas sociais. (Silva, Moura e Junqueira, 2015)

Melo Neto e Froes (2002) abordam a construção de redes locais a partir dos seguintes aspectos:

“a) cria novas interações entre as pessoas, fortalecendo laços de amizade, familiares e novas opções de trabalho e recreação;

b) ajuda a moldar as práticas e valores individuais, grupais e coletivos, aguçando a percepção e a visão social das pessoas;

c) conecta indivíduos, grupos, regiões e organizações;

d) ajuda a construir novas formas de convivência;

e) contribui para a superação de problemas sociais através da definição coletiva de objetivos, articulação de pessoas e instituições;

f) disponibiliza "saberes distintos" e os coloca a serviço do interesse coletivo;

g) constrói vínculos mais fortes e consistentes entre as pessoas, grupos e instituições;

h) promove acordos de cooperação e alianças;

i) cria e amplia alternativas de ação." 
Estas redes têm como características a dinâmica, flexibilidade e a mutabilidade, e como consequência a longevidade, eficácia e eficiência dos negócios, resultando no aparecimento, desenvolvimento e manutenção de variáveis culturais e sociais e de processos tecnológicos (Bitante, 2019). Ao movimentar-se em rede e suas relações, os empreendimentos sociais têm seus projetos desenvolvidos graças à convergência de esforços numa mesma direção, além de incentivar e promover o desenvolvimento pessoal de competências de atores da rede e consequentemente, há o fortalecimento organizacional que altera positivamente a realidade dos indicadores sociais, econômicos e políticos.

As externalidades negativas provocadas por diferentes usos não sustentáveis dos recursos naturais torna os indivíduos cada vez mais atentos às mudanças provocadas na sociedade e ao meio ambiente, tornando-se agentes impulsionadores de mudanças sociais e ambientais. Essa transformação de valores na sociedade está alterando os conceitos tradicionais de empresas, obrigando-as a buscarem não somente o lucro, mas valores sociais (Duarte, Madruga e Becker, 2013) que abrem caminho para novos olhares e buscam o casamento perfeito entre uso sustentável dos recursos naturais, desenvolvimento econômico e equidade social.

O desenvolvimento sustentável tem no empreendedorismo social, nos negócios sociais e nas redes de relacionamento, a possibilidade de gerar ações inovadoras por organizações que atuam tanto no setor público como no privado, com o objetivo de promover a transformação social, através da geração de empregos e correção de externalidades, provocadas por um único indivíduo ou por um único grupo de indivíduos, afetando assim, a utilidade de outros indivíduos sem a devida compensação por esse efeito, gerando uma externalidade ou falha de mercado (Krugman \& Wells, 2015).

Duarte, Madruga e Becker (2013), lembram que na busca do desenvolvimento sustentável, existem alguns caminhos, desafios e atitudes que podem conduzir o empreendedorismo social como uma das principais alternativas para as empresas manterem-se competitivas. Assim, o ES visa beneficiar as organizações sociais, proporcionando meios para se alcançar a sustentabilidade tão almejada pelas empreendedores sociais e também pelas organizações com fins lucrativos, ampliando suas possibilidades de consolidação no mercado e auxiliando na correção das falhas de mercado. Vale ressaltar que essas iniciativas vão além do mero aumento dos ativos financeiros e da geração de renda e empregos dos indivíduos e consequentemente de suas familiares envolvidos, incluindo-se portanto, o acesso à moradia, serviços de saúde e educação de qualidade.

Conforme Bastos e Teodósio (2017), as novas concepções de trabalho têm contribuído para maior valorização da habilidade empreendedora, traduzindo-se no aumento das opções financeiras e técnicas, que apoiam essa tendência, considerando o empreendedor como um agente revelador e um impulsionador do crescimento e desenvolvimento econômico da sociedade, gerando riquezas e inovações de todos os tipos nas organizações contemporâneas, acoplando práticas de mercado e visão empresarial ao desenvolvimento do capital humano e sugerindo soluções para problemas sociais.

Os pequenos negócios no Brasil, corresponderam a mais de um quarto do Produto Interno Bruto (PIB) nacional em 2011, representado pelas micro e pequenas empresas. Um resultado que vem crescendo nos últimos anos, passando de $21 \%$ em 1985 para $27 \%$ em 2011 (Sebrae, 2015). Entretanto, ainda não existe uma iniciativa concreta por parte da União em 
relação ao desenvolvimento da temática do empreendedorismo social no país. Não estando, esta temática, inserida na agenda nacional como uma prioridade ou como meio para o fortalecimento da economia local e nacional, quer seja social, solidária e criativa por meio de políticas públicas.

Para autores como Leão, Moutinho e Xavier (2012), as instituições sociais estão buscando validações por meio de um movimento de cooperativismo integrado, onde a interação e a cooperação acabam por levar a um aumento no capital social e econômico da empreendimento. Os autores partem do pressuposto de que as instituições empreendedoras se consolidam como elementos relevantes para o desenvolvimento de um determinado território; afirmando que parcerias com órgãos estatais e instituições privadas podem ajudar na consolidação das práticas sociais por meio de doações e parcerias.

Diversos são os empreendimentos sociais no Brasil que angariaram êxito com a prática da cooperação entre os stakeholders para o atendimentos de demandas sociais $\mathrm{e}$ consequentemente, auxiliando o governo para a correção das falhas de mercado.

Nesse âmbito, empreender socialmente surge como ferramenta para promoção da cidadania e resolução de problemas sociais e ambientais. Este desígnio tem motivado o surgimento de várias organizações e startups, empresas de inovação e base tecnológica, que conjugam os resultados financeiros à geração de benefícios para uma comunidade carente de serviços básicos, como educação, saúde, moradia, emprego e outros.

Regionalmente, existem vários exemplos desse tipo de iniciativas que promovem o empreendedorismo social. Bose (2012) em seu estudo, traz o exemplo de um empreendimento social que objetiva a promoção do desenvolvimento social em âmbito territorial. Criado a partir da iniciativa pioneira da criação de um fundo composto e gerido por: organizações da sociedade civil, iniciativa privada, poder público e lideranças locais, intitulado: Fundo Zona Leste Sustentável. Inspirados por modelos de fundos comunitários, essa iniciativa localiza-se nos distritos de São Miguel Paulista, Ermelino Matarazzo e Itaim Paulista, localizados no município de São Paulo. A missão do fundo é canalizar recursos de pessoas físicas e jurídicas que tenham interesse em promover o desenvolvimento da região de forma monitora em arranjos produtivos locais de maneira a atingirem competitividade no mercado e gerem novo empregos e renda no território.

Outro exemplo importante no conjunto de iniciativas sociais, é a existências das Empresas Juniores (EJ) presente nas universidades, ao passo que, através delas os empreendedores sociais podem ter acesso a inúmeros serviços de qualidade por um preço acessível que não poderia pagar, caso buscassem no mercado. Aumentando assim, as suas chances de permanência no mercado em sua fase inicial, ampliando a sua capacidade para desenvolver novos produtos ou processos ou para ganhar e criar conhecimento via EJ (Aveni \& Ferreira, 2016).

O Graac é exemplo de empreendimento social que surge em 1991, para atender a demanda da sociedade quanto ao atendimento de crianças com câncer. A entidade já tratou mais de 5 mil pacientes, com uma taxa de cura que fica em torno de $70 \%$. A organização funciona com base em um rigoroso sistema de gestão e atendimento que envolve pesquisadores de universidades, a iniciativa privada e a sociedade.

O Instituto Atlântida é um dos poucos exemplos que o país possui relacionado a empreendimentos sociais que visam a correção de externalidades ligadas ao meio ambiente. 
O instituto surge em 2001, como fruta da parceria de jovens de vários estados brasileiros em diminuir a degradação ambiental oceânica. Fundada com o intuito de desenvolver projetos ambientais sustentáveis em toda a zona oceânica do Nordeste brasileiro. "Os projetos desenvolvidos buscam identificar a problemática ambiental, seus níveis de degradação, e realizar análises de todas as necessidades ambientais, sejam estas de degradação e ou recuperação/ correção de agressões provocadas no litoral nordestino (Mendonça, Miranda e Ferraz, 2015)

O Banco Pérola, presente na cidade de Sorocaba, interior do estado de São Paulo,um exemplo de negócio social inspirado no modelo de negócio de Yunus, o empreendedor do Grameen Bank. O banco criado é uma organização com formato legal de Organização da Sociedade Civil de Interesse Público ou OSCIP creditícia desenvolvida para oferecer microcrédito produtivo orientado para empreendedores à margem da pobreza na cidade paulista (do Nascimento et. al, 2012).

Essas e outras iniciativas empreendedoras são fundamentais para o desenvolvimento do país e a geração de empregos. Por esta razão, a adequação do empreendedorismo social as realidades sociais e ambientais, com intuito de correção das falhas de mercado, pedem que os empreendedores e fazedores de políticas públicas obtenham boas práticas de governança, que foquem tanto na criação de valor social quanto de valor econômico (Hill, Kothari \& Shea, 2010; Dacin, Dacin \& Tracey, 2011; Limeira, 2015). Nesse caso, o benefício social consiste no fato de que os lucros e o crescimento do capital social produzidos pelos empreendimentos sociais servirão para beneficiar os indivíduos à margem da sociedade, ajudando-os a melhorar a sua condição de pobreza, atingindo melhores condições de vida (Yunus, 2008), além de auxiliar o governo nas correções de externalidades negativas.

\section{Discussão e Considerações Finais}

$\mathrm{Na}$ tentativa de encontrar soluções para combater as constantes crises que abalam as sociedades, a economia de mercado vigente não mais atende as questões vivenciadas nas comunidades. Portanto, uma busca constante por novos modelos de gestão, em todas as áreas e setores que demandam o desenvolvimento é fundamental (Mourão, Engler e Oliveira, 2019). Assim, há necessidade de reformulação das ferramentas tradicionais que levam ao desenvolvimento nas economias modernas, uma vez que estas não mais se baseiam na grande produção e consumo de bens e serviços exclusivamente, mas buscam a geração de inovações gestacionais que auxiliam na correção de externalidades provocadas por desequilíbrios entre as necessidades humanas e os recursos naturais disponíveis.

Faz-se, portanto, necessário o incentivo aos empreendimentos que agreguem valor econômico e social a fim de minimizar a acentuada pressão sobre os recursos naturais, de forma a reorganizar os sistemas econômicos produtivos, via ações de política pública que premiem tais empreendimentos. Tendo em vista que, as externalidades, de acordo com a teoria econômica, devem ser sanadas por meio de ações do Estado, uma vez que, bens ou serviços que produzem externalidades não são oferecidos eficientemente (Keynes, 1936). Desse modo, percebe-se que o empreendedorismo social em uma estrutura integrada, pode ser capaz de promover o desenvolvimento econômico sustentável, auxiliando na correção das falhas de mercado, gerando emprego digno e produtivo para os envolvidos, por meio de práticas que incentivem a geração e agregação de valor social e econômico, além de boas 
práticas de governança e incentivos positivos que levam o empreendedor a inovar e criar novas empresas sociais.

O crescimento econômico inclusivo e sustentável, emprego pleno e produtivo e trabalho decente para todos não é uma meta fácil de se alcançar, sobretudo no Brasil e países onde as relações socioeconômicas são díspares. Por essa razão, as competências empreendedoras sociais necessitam estar interligadas ao crescimento, desenvolvimento e surgimento de novas empresas que se beneficiem das externalidades negativas, transformando e auxiliando o governo a corrigi-las e assim recebam como contrapartida do governo subvenções, subsídios ou incentivos, que permitam a sua consolidação no mercado.

Estas redes têm como características a dinâmica, flexibilidade e a mutabilidade, e como consequência a longevidade, eficácia e eficiência dos negócios, resultando no aparecimento, desenvolvimento e manutenção de variáveis culturais e sociais e de processos tecnológicos (Bitante, 2019). Essas características são essenciais no desenvolvimento sustentável das empresas sociais, visto que as práticas integradas com as redes sociais e o desenvolvimento sustentável oferecem mecanismos que auxiliam a sobrevivência das empresas sociais no mercado.

Desta forma, este trabalho contribui com a literatura ao trazer uma discussão que sugere o empreendedorismo social em uma estrutura integrada como um veículo de promoção do desenvolvimento econômico local e sustentável, via correção das falhas de mercado e gera, portanto, não apenas renda e emprego digno e produtivo para os envolvidos, mas age como veículo para uma melhora na sua condição de bem estar social.

Conclui-se portanto, que a abordagem do empreendedorismo social aliado a redes sociais colaborativas integradas podem levar países como o Brasil a alcançar o Objetivo oito para um Desenvolvimento Sustentável, proposto pela ONU e conquistar resultados operacionais, econômicos e sociais de maneira eficiente do que em sua atuação isolada.

\section{Referências Bibliográficas}

Austin, J., Stevenson, H., \&amp; Wei-Skillern, J. Social and commercial entrepreneurship: Same, different, or both? RAUSP-Revista de Administração da Universidade de São Paulo, v.47, $\mathrm{n}^{\circ}$ 3, pág:370-384, 2012. Recuperado em 28 de outubro de 2019, de http://dx.doi.org/10.5700/rausp1055>.

Aveni, A. \& Ferreira, H.R. Empreendedorismo social: a inovação do movimento das empresas Júnior no Brasil. Universitas: Gestão e TI, vol. 6, $\mathrm{n}^{\circ}$ 2, 2016. Recuperado em 22 de outubro de 2019, de http://dx.doi.org/10.5102/un.gti.v6i2.3871 >.

Bastos, M. F.; Vale, G.M.V.; Teodósio, A. dos S. de. Redes, Empreendedorismo Social e Negócios Inclusivos: em busca de um modelo compreensivo sobre inovação no combate à pobreza na América Latina. Academia ICE, 2017. Recuperado em 10 de outubro de 2019, de < http://ice.org.br/blog/wp-content/uploads/2017/09/M.-Flavia-RedesEmpreendedorismo-Social-e-Neg\%C3\% B3cios-Inclusivos-em-busca-de-um-modelocompreensivo-sobre-inova\%C3\%A7\%C3\%A3o-no-combate-\%C3\%A0-pobreza-naAm\%C3\%A9rica-Latina.pdf $>$. 
Bitante, A. P. As implicações da liderança no desenvolvimento e manutenção de conglomerações regionais. 211 p, 2019. Pós- Doutoramento (Programa de PósDoutorado) - Universidade Federal do ABC.

Bose, M. Empreendedorismo social e promoção do desenvolvimento local. Tese (Doutorado em Administração) - Faculdade de Economia, Administração e Contabilidade, Universidade de São Paulo, São Paulo, 2013. Recuperado em 16 de outubro de 2019, de doi:10.11606/T.12.2013.tde-27032013-170655.

Bourdieu, P. \& Wacquant, L. An Invitation to Reflexive Sociology, University of Chicago Press, Chicago, IL and London, 1997.

Comini, G.; Barki, E.; Aguiar, L. T. A three-pronged approach to social business: a Brazilian multi-case analysis. RAUSP-Revista de Administração da Universidade de São Paulo, v. 47, n. 3, p. 385-397, set. 2012. Recuperado em 19 de setembro de 2019 de http://www.scielo.br/pdf/rausp/v47n3/04.pdf

Da Silva, A. R.; Sousa, L. F. F; Godói-De-Sousa, E. O Empreendedorismo Social Analisado a partir de Práticas Sociais do Setor Privado: uma descrição e uma análise das escolhas estratégicas e do estabelecimento de parcerias da empresa norte-americana Toms Shoes. $\begin{array}{lllllll}\text { Recuperado em } & 24 & \text { de } & \text { outubro } & \text { de } & 2019 & \text { de }\end{array}$ https://revistas.unifacs.br/index.php/rgb/article/view/4445

Dacin, M.; Dacin, P.; Tracey, P. Social entrepreneurship: A critique and future directions. Organization Science, 22(5), p. 1.203-1.213, 2011. Recuperado em 05 de setembro de 2019

https://pdfs.semanticscholar.org/ec61/4c4f636aeeb6ea10accddfcb1a2f7a1ce603.pdf

Dees, J. G., 1998. The Meaning of "Social Entrepreneurship".

Desai, H.P. Business Models for Inclusiveness. Social and Behavioral Sciences. Vol. 157, p. 353- 362, 2014. Recuperado em 12 de outubro de 2019 de https://isfcolombia.uniandes.edu.co/images/201519/LRD5.pdf

Duarte, T.L.; Madruga, L. R da R. G.; Becker, D.V. \& Ávila, L. V. Desenvolvimento sustentável e empreendedorismo social: um estudo multicaso sobre o impacto de um programa social em organizações não governamentais. Revista UNIABEU Belford Roxo, vol.6, $\mathrm{n}^{\mathrm{o}}$ 14, ISSN 2179-5037, setembro- dezembro 2013. Recuperado em 25 de outubro de 2019 de http://www.anegepe.org.br/edicoesanteriores/brasilia/[20].pdf

Ducci, N. P. C.; Teixeira, R. M. As redes sociais dos empreendedores na formação do capital social: um estudo de casos múltiplos em municípios do norte pioneiro no estado do Paraná. Cad. EBAPE.BR, Rio de Janeiro , v. 9, n. 4, p. 967-997, Dec. 2011. 
Recuperado em $19 \quad$ de setembro de 2019, de $<$ http://www.scielo.br/scielo.php?script=sci_arttext\&pid=S1679$39512011000400003 \& \operatorname{lng}=\mathrm{en} \& \mathrm{nrm}=\mathrm{iso}>$.

El Ebrashi, R A teoria social empreendedorismo e impacto social sustentável. Jornal de Responsabilidade Social, vol. 9, n 2 pág. 188-209, 2013. Recuperado em 16 de outubro de 2019, de http://dx.doi.org/10.1108/SRJ-07-2011-0013 >.

Filion, L. J. Empreendedorismo: empreendedores e proprietários - gerentes de pequenos negócios. Revista de Administração, v. 3, n. 2, p. 05 - 28, 1999. Recuperado em 29 de outubro de 2019, de http://www.spell.org.br/documentos/ver/18122/empreendedorismo-empreendedores-e-proprietarios-gerentes-de-pequenos-negocios

Hill, T.; Kothari, T.; Shea, M. Patterns of Meaning in the Social Entrepreneurship Literature: A Research Platform. Journal of Social Entrepreneurship, 1, p. 5-31, 2010. Recuperado em 13 de setembro de 2019, de https://www.researchgate.net/publication/233093161_Patterns_of_Meaning_in_the_Soci al_Entrepreneurship_Literature_A_Research_Platform

Ipea - Instituto De Pesquisa Econômica Aplicada. Diagnóstico sobre catadores de resíduos sólidos. Brasília: Ipea, 2012. Recuperado em 23 de outubro de 2019, de http://www.ipea.gov.br/portal/images/stories/PDFs/relatoriopesquisa/120911_relatorio_c atadores_residuos.pdf $>$.

Jiao, H. A conceptual model for social entrepreneurship directed toward social impact on society. Social Enterprise Journal, vol. 7 n. 2, pág: 130-149, 2011. Recuperado em 04 de setembro de 2019, de https://doi.org/10.1108/17508611111156600 >.

Krugman, P.; Wells, R. Manual de Introdução à Economia. $3^{\text {a }}$ ed. pág. 992. Elsevier, 2015.

Iizuka, E.; Walchhutter, S.; Romani-Dias, M.; Barbosa, A. Empreendedorismo Social e Negócios Sociais: Revisão crítica e agenda de pesquisa, 2014. Recuperado em 28 de outubro de 2019, de https://www.researchgate.net/publication/319451200_Empreendedorismo_Social_e_Neg ocios_Sociais_Revisao_critica_e_agenda_de_pesquisa.

Limeira, T. Empreendedorismo Social no Brasil: Estado da Arte e Desafios, 2015. Recuperado em 28 de outubro de 2019, de http://ice.org.br/wpcontent/uploads/pdfs/Empreendedorismo_Social_no_Brasil_ICE_FGV.pdf.

Machado, M. C. R.; Lenzi, F. C.; Verdu, C. P. Empreendedorismo Social: fronteiras teóricas das escolas. XX SEMEAD Seminários em Administração, Faculdade de Economia, Administração e Contabilidade da Universidade de São Paulo, 2017. Recuperado em 16 de outubro de 2019, de http://login.semead.com.br/20semead/arquivos/1205.pdf. 
Mair, J.; Marti, I. Social entrepreneurship research: A source of explanation, prediction, and delight. Journal of World Business, 41(1), 36-44, 2006. Recuperado em 22 de setembro de 2019, https://www.researchgate.net/publication/222436408_Social_Entrepreneurship_Research _A_Source_of_Explanation_Prediction_and_Delight

Marques, E. Os mecanismos relacionais. Revista Brasileira de Ciências Sociais, vol $22 \mathrm{n}^{\mathrm{o}}$ 64, pág:157-161, 2007. Recuperado em 25 de setembro de 2019, de http://www.scielo.br/pdf/rbcsoc/v22n64/a13v2264.pdf

Meirelles, D. S. Teorias de mercado e regulação: por que os mercados e o governo falham?. Cadernos EBAPE.BR, 8(4), 644-660, 2010. Recuperado em 23 de outubro de 2019, de https://dx.doi.org/10.1590/S1679-39512010000400006

Mendonça, C. M. O.; Miranda, R. O.; Ferraz, S.F. de S. Empreendedorismo social e a geração de recursos próprios em ongs cearenses. CONTEXTUS Revista Contemporânea de Economia e Gestão. Vol 13 - No 2 - mai/ago 2015.

Mourão, N. M.; Engler, R. C.; Oliveira, A. C. C. Diversidade Cultural e Tecnologias Sociais: estudos para incentivar a autogestão de comunidades do Brasil e Argentina. RELACultRevista Latinoamericana de Estudios en Cultura y Sociedad | Latin American Journal of Studies in Culture and Society V. 05, ed. especial, mai., 2019, artigo n ${ }^{\circ}$ 1540, e-ISSN: 2525-7870. Recuperado em 09 de setembro de 2019, de http://periodicos.claec.org/index.php/relacult/article/view/1540

Musgrave, R. A. Teoria das Finanças Públicas. Um Estudo de Economia Governamental, 1976. 2a ed. Editora Atlas.

Oliveira Pinto, H. F.. O catador de resíduos sólidos e sua função como empreendedor social numa visão contemporânea. Entrepreneurship, v.3, n.1, p.26-31, 2019. Recuperado em 17 de outubro de 2019, de http://doi.org/10.6008/CBPC2595-4318.2019.001.0004

Oliveira, E. M. Empreendedorismo social no Brasil: atual configuração, perspectivas e desafios - notas introdutórias. Curitiba, Rev. FAE, v.7, n.2, p.9-18, jul./dez. 2004. Recuperado em 24 de setembro de 2019, de https://revistafae.fae.edu/revistafae/article/view/416

Recuero, R. Redes sociais na internet. Porto Alegre: Sulina, 2009. Recuperado em 18 de setembro de 2019, de http://www.ichca.ufal.br/graduacao/biblioteconomia/v1/wpcontent/uploads/redessociaisnainternetrecuero.pdf 
Recuero, R. Comunidades em redes sociais na Internet: um estudo de caso dos fotologs brasileiros. Liinc em Revista, v.4, p.63-83, 2008. Recuperado em 17 de outubro de 2019, de http://revista.ibict.br/liinc/index.php/liinc/article/view/254>.

Seelos, C., \& Mair, J. Social Entrepreneurship: Creating New Business Models to Serve the Poor. Business Horizons, 48(3), 241-246, 2005. Recuperado em 13 de outubro de 2019, de

https://www.researchgate.net/publication/4885197_Social_Entrepreneurship_Creating_N ew_Business_Models_to_Serve_the_Poor

Silva, M. F.; Moura L. R.; Junqueira, L. A. P. As Interfaces entre Empreendedorismo Social, Negócios Sociais e Redes Sociais no Campo Social. Revista de Ciências da Administração, Florianópolis, p. 121 - 130, ago. 2015. ISSN 2175-8077. Recuperado em 27 de outubro de 2019, de https://periodicos.ufsc.br/index.php/adm/article/view/2175$8077.2015 \mathrm{v} 17 \mathrm{n} 42 \mathrm{p} 121$

Spear, Roger (2006). Social entrepreneurship: a different model?. International Journal of Social Economics. vol 33. n.5/6, 399-410. Recuperado em 19 de outubro de 2019, de https://doi.org/10.1108/03068290610660670

Vilar, D. L. F. Disparidade de renda e condições sociais: o Programa Bolsa Família e a distribuição de renda no nordeste, 2000 a 2010. 2017. 65 f. Dissertação (Mestrado em Economia Aplicada) - Faculdade de Economia, Administração e Contabilidade, Programa de Pós-Graduação em Economia Aplicada, Universidade Federal de Alagoas, Maceió, 2017. Recuperado em 19 de outubro de 2019, de http://www.repositorio.ufal.br/handle/riufal/3024

Yunus, M. Criando um Negócio Social. Rio de Janeiro: Campus, 2010.

Yunus, M. Um mundo sem pobreza: a empresa social e o futuro do capitalismo. São Paulo: Ática, 2008.

Zahra, S.A., Rawhouser, H.N., Bhawe, N., Neubaum, D.O. and Hayton, J.C. Globalization of social entrepreneurship opportunities. Strategic Entrepreneurship Journal, vol. 2, no 2, pág: 117-31, 2008. Recuperado em 26 de outubro de 2019, de https://doi.org/10.1002/sej.43 